\title{
Os espaços para a educação física no ensino secundário paranaense: um estudo comparativo entre os anos finais da ditadura varguista e os anos da ditadura militar brasileira pós 1964
}

\section{The spaces for physical education on the secondary education in Paraná: a comparative study between the final years of the Vargas dictatorship and years of Brazilian military dictatorship after 1964}

\author{
Marcus Aurélio Taborda de Oliveira ${ }^{1}$ \\ Sergio Roberto Chaves Junior ${ }^{2}$
}

\begin{abstract}
RESUMO
Neste estudo comparativo pretendemos contemplar os diversos entendimentos e as diversas prescrições para a Educação Física escolar na segunda metade da década de 1940, e na primeira metade dos anos 70 do século passado no Estado do Paraná, Brasil. Como fonte privilegiamos as Diretrizes para a Educação Física nos Estabelecimentos de Ensino Secundário, de 1947, além de depoimentos de professores escolares e alguns números da Revista Brasileira de Educação Física e Desportos, dos anos 70. Nosso foco está centrado na redefinição das prescrições curriculares no que se refere ao espaço apropriado para as aulas daquela disciplina, tenham sido ou não edificados, mas que configurariam uma nova forma de conceber o ensino da disciplina, na segunda metade do séc. XX, fortemente ancorado nas práticas esportivas. Mais do que afirmar a máxima de que "o espaço educa e conforma", apresentamos como essas mudanças aconteceram pelo menos
\end{abstract}

1. Doutor em História e Filosofia da Educação/Universidade Federal do Paraná - Conselho Nacional de Desenvolvimento Científico e Tecnológico/CNPq.

2. Mestre em Educação/Faculdade Guairacá-PR. 
no âmbito das prescrições relacionadas à disciplina de Educação Física, ajudando a redefinir o seu sentido dentro da escola secundária brasileira. Trata-se, assim, de perspectivar a reconfiguração do espaço tanto quanto os seus usos possíveis, autorizados ou não. Nossas análises concluem que muitas recomendações que propalavam a redefinição espacial da Educação Física foram plenamente desenvolvidas, indicando assim que a disciplina ganharia um "espaço" próprio novo e mais vigoroso dentro dos diversos e plurais espaços da instituição escolar, até mesmo pelo grande volume de recursos financeiros envolvidos na sua efetivação.

Palavras-chave: história da educação; história do currículo; história das disciplinas escolares; arquitetura escolar.

\begin{abstract}
This comparative study intends to analyze some understandings and prescriptions of the Physical Education subject in the second half of the 1940's and the first half of 1970's in the state of Paraná, Brazil. This study uses as sources the Diretrizes para a Educação Física nos Estabelecimentos de Ensino Secundário, from 1947, some testimonies of school teachers and some issues of Revista Brasileira de Educação Física e Desportos, from the 1970's. The focus is on the processes of curricular prescriptions redefinitions, mainly on the understanding of what the appropriate space for Physical Education classes was, have them been built or not. That represented a new way of figure out the teaching of this subject in the second half of the $20^{\text {th }}$ century, strongly anchored in sports. More than show the affirmation "the space educates and conforms", this article presents how those changes occurred in the Physical Education subject, helping to redefine its meaning in the Brazilian secondary school. These analyses conclude that many recommendations that disseminated the redefinition of Physical Education spaces were fully developed, indicating that the subject would gain a own "space", new and more vigorous in the diverse and plural school's area, because the large financial resources involved in their effectiveness.
\end{abstract}

Keywords: history of education; history of curriculum; subjects' history; school's architecture.

Os estudos sobre o currículo, sobretudo em sua dimensão histórica, têm contribuído significativamente para uma compreensão mais acurada daquilo que pode ser caracterizado como culturas escolares (VIÑAO, 1995). Entre as di- 
mensões que as compõem, o espaço e o tempo assumem um significado inaudito por, de distintas maneiras, contribuírem para a definição de outros dispositivos escolares, tais como as rotinas, as práticas, os rituais, os saberes, estejam esses disciplinados ou não. Não só no Brasil, desde os finais do séc. XIX o espaço escolar se configurava como um elemento capaz de, em si mesmo, representar a modernidade pedagógica, tão marcada pela higiene e pela noção de civilização, ambas fundamentadas em um legado cientificista.

Procuramos neste trabalho localizar em dois períodos distintos da história da escolarização no Brasil a retórica que afirma a redefinição do espaço como condição da melhoria da qualidade da educação oferecida nas escolas. Optamos por uma perspectiva diacrônica e focamos nosso olhar em duas expressões do conservadorismo político que teve a sua máxima realização nos períodos autoritários de 1930-1945 e 1964-1985. Esses períodos não foram monolíticos na sua forma e no seu conteúdo, mas têm como característica comum uma ênfase em governos militares que, em diferentes momentos, assumem a forma ditatorial. O primeiro período aqui destacado é marcado pela presença militar de uma oficialidade média, sobretudo decorrente do movimento denominado tenentismo, com forte presença na cena política a partir da década de 1920. Tem a sua expressão mais acabada em Getúlio Vargas, que governou o Brasil de 1930 a 1945 e de 1951 a 1954, quando se suicidou. Já o segundo período, inequivocamente reconhecido como ditadura militar, tem o seu início em 1964 com o golpe militar que depôs o presidente João Goulart. O período se encerra em 1985 com a volta das eleições diretas, depois de cinco presidentes militares de alta patente impostos ao país. Entre outros elementos, ambos os períodos se caracterizam por uma ênfase profundamente desenvolvimentista, nacionalista e populista, ainda que com matizes diferençados.

Do ponto de vista do objeto focalizamos a experiência de reestruturação do Colégio Estadual do Paraná (CEP), modelo escolar público para o ensino secundário, no primeiro período aqui demarcado. Para o segundo período nos valemos de uma análise da rede pública de ensino da cidade de Curitiba, capital do estado, no que se refere ao que ficaria estabelecido como $1 .^{\circ}$ grau com a Lei $5692 / 71$. Na verdade, a referida lei reorganiza o ensino brasileiro em dois graus, sendo que o primeiro grau passa a comportar o que antes daquela data fazia parte do ensino secundário. Assim, nosso foco privilegia o que em diferentes momentos da história da educação brasileira foi o ensino secundário, direcionado aos estudos imediatamente posteriores ao ensino primário. A primeira escolha decorre do caráter modelar do Colégio Estadual do Paraná. A segunda, pela criação na década de 1960 da rede pública de Curitiba, que tinha como um dos seus motores a construção de novos e "adequados" edifícios escolares. Nas duas experiências públicas e estatais, uma no âmbito estadual, outra no 
âmbito municipal, procuraremos mostrar como o ensino de Educação Física foi concebido a partir da redefinição de um determinado padrão espacial, que tinha o esporte como conteúdo privilegiado.

\title{
Necessidades "modernas" da educação: o espaço escolar no giná- sio paranaense nas décadas de 1930 e 1940
}

Mesmo sendo considerada uma instituição modelar do ensino secundário paranaense à época, o Ginásio Paranaense $(\mathrm{GP})^{3}$ apresentava alguns problemas estruturais que limitavam os usos de espaços e dos conteúdos da disciplina de Educação Física entre os finais dos anos de 1930 e início dos anos 1950. Vejamos o que pensavam algumas autoridades, como Aldo Penteado de Almeida, Inspetor Federal do Ginásio Paranaense:

\begin{abstract}
Aumentando sobre modo de ano para ano o corpo discente deste Ginásio, a medida do crescimento vertiginoso da população escolar do Estado, já se tornou deficiente o prédio atual para o fim a que se destina. Sob todos os pontos de vista, não satisfazem as suas instalações. Há falta de salas. Exíguo é o espaço destinado ao recreio. Nos dias de chuva o saguão interno ainda menos comporta os alunos, que, ali, se comprimem, se acotovelam, num ambiente falto de luz e de ar. [...] Quero falar do espaço, que é imprescindível e urgente alargar, sob a pena de se limitar a matrícula, em prejuízo da educação da modernidade (ARQUIVO GERAL DO COLÉGIO ESTADUAL DO PARANÁ, 1937).
\end{abstract}

A questão do espaço escolar parece ao signatário a mais relevante, pois poderia prejudicar a "educação da modernidade". Note-se que se destaca a necessidade de ampliação da escolarização, bem como as condições higiênicas para o desenvolvimento dos alunos. Aliás, a questão da higiene parece ser a que mais preocupava o inspetor. $\mathrm{O}$ fato dos alunos não poderem participar do recreio

3. Para um entendimento da história do Colégio Estadual do Paraná (CEP), ver Ernani Straube, 1993. Para o autor, o CEP teve início em 1846, quando da criação do Licêo de Coritiba. No entanto, como aponta esse mesmo autor, essa instituição teve suas atividades extintas por duas vezes na década de 1870, o que talvez possa infirmar uma continuidade da instituição. O que interessa no presente estudo é que desde 1892 essa instituição era conhecida como Ginásio Paranaense. Em 1942, pelo decreto federal n. ${ }^{\circ} 614$ de 10/06/1942, sua denominação passou a ser Colégio Paranaense e no ano seguinte pelo decreto estadual n. ${ }^{\circ} 1358$ de 25/03/1943, passou a possuir a denominação atual, Colégio Estadual do Paraná. As denominações dessa instituição, ao longo do estudo, serão alteradas conforme a cronologia exposta acima. 
- criado exatamente segundo preceitos higienistas para evitar a surmenage poderia trazer prejuízos aos alunos e à reputação da instituição, reconhecida pela qualidade do ensino. A situação problemática em que se encontrava o GP, no que se refere ao espaço interno, não poderia continuar por muito tempo, na opinião do inspetor.

Nessa mesma década de 1930 podemos localizar também o início de uma discussão, entre as autoridades daquela instituição, sobre os cuidados com educação física dos alunos. As exigências com base nos cuidados higiênicos da formação física, moral e intelectual dos alunos, proclamadas desde o séc. XIX, pelo menos, eram coevas com os discursos em torno da afirmação na nação. Logo, é preciso pensar a valorização da educação física como parte de um projeto de reestruturação da cultura nacional.

Consequentemente, o debate sobre a construção do novo prédio para o educandário privilegiaria também os espaços necessários para o desenvolvimento das aulas de Educação Física. Em determinado momento desses debates, as exigências para as instalações da educação física eram "1 salão de recreio para os alunos, 1 salão de recreio para as alunas, 1 salão amplo para os exercícios de ginástica, 1 pátio arborizado para recreio" (MUSEU DO CEP, 1934). Essas solicitações dão indícios de quais seriam os pressupostos das aulas de Educação Física daquele momento histórico: aulas com ênfase nos exercícios ginásticos, com fins higiênicos e de fortalecimento dos corpos. Como resultado desse entendimento, parece-nos que não havia a necessidade de outras instalações para a educação física, para além de espaços amplos e arejados. Enquanto a construção do novo prédio não era uma realidade, alguns outros espaços foram disponibilizados para as aulas de Educação Física do GP/CEP, já que a instituição possuía apenas um pátio de pequenas proporções. Praças públicas, quadras, ginásios e estádios de clubes particulares, entre outros, fizeram parte do repertório de espaços utilizados ao longo das décadas de 1930 e 1940 (CHAVES JUNIOR, 2004), denotando um grande grau de improvisação da parte do gestor público. Não obstante, um aspecto importante a ser considerado é o surgimento paulatino de uma outra orientação dos espaços utilizados para a Educação Física. Nesses espaços, além dos equipamentos próprios das práticas dos “antigos" exercícios ginásticos (pórticos, barras e traves de equilíbrio, entre outros), existia a possibilidade de utilização dos espaços com outras práticas, especialmente a prática esportiva.

Alguns sinais dessa outra orientação das aulas de Educação Física podem ser depreendidos do depoimento do Professor Mario Bassói ${ }^{4}$, entre outros:

4. Mario Bassói, ex-professor de Educação Física do CEP (lecionou de 1942 a 1948) e exinspetor federal de Educação Física e do MEC. 
Dentro do espaço que você podia, dava o aquecimento, fazia aquela parte para aquecer o organismo, os músculos, tudo mais, e depois então você fazia uma corrida, fazia salto em altura, salto em extensão [...] A gente fazia o que podia dentro da parte esportiva, porque só aquecimento, só ginástica não adianta (MÁRIO BASSÓI, 2003, p. 7).

A atratividade proporcionada pelas práticas esportivas também faz parte das lembranças de alguns antigos professores daquela instituição. Aquele era um momento de transição das aulas com base na gymnastica, para as aulas com ênfase nos esportes. A utilização de jogos já era há tempos um artifício de relativo sucesso para os professores (VAGO, 1999; LINHALES, 2006).

Se as condições para o desenvolvimento das aulas de Educação Física destinadas aos meninos pareciam ser precárias, considerando o "ideal" proposto pelos regulamentos do ensino secundário, para as meninas que estudavam no GP/CEP a situação parecia ser um pouco mais grave, professoras, espaços, conteúdos e materiais eram algumas das carências vividas aquela época:

Então não tinha local, absolutamente nada. Era numa sala, que afastávamos as cadeiras e eu subia em cima da mesa para poder mostrar os exercícios - naquela época nós usávamos o Método Francês - e elas me seguiam. Então era muito restrita a aula. Muito restrita. E era dentro de uma sala. Não fazíamos jogos nem nada disso. Era exclusivamente aquela aula. [...] Jogar bola, exercícios com bola, não tinha condição, não tinha espaço. Então eram só mesmo os exercícios, não é? (IVETE LUZ BUCK SILVA, 2004, p. $7-8)^{5}$.

A precariedade de espaço fazia com que as professoras tivessem que improvisar, dando as aulas no interior da própria escola, no espaço restrito das salas de aula. Embora os relatórios de Educação Física do GP da década de 1940 apontassem para a existência de locais específicos para a prática da Educação Física feminina, parece que esses não eram utilizados de forma sistemática.

A partir desses problemas relacionados ao andamento das aulas de Educação Física - e certamente as dificuldades não eram exclusividade dessa disciplina - adaptando espaços e conteúdos, a construção de um novo prédio para o CEP tornava-se ainda mais fundamental para manter uma suposta qualidade de ensino ostentada pela tradicional instituição de ensino secundário parana- 
ense. Quando do lançamento da pedra fundamental do novo prédio realizado em 19/04/1943, havia a promessa de ampliar consideravelmente o espaço do CEP e atender, também, às exigências da Educação Física. Essa obra possuía um grande significado, pois a sua construção era tida como uma das maiores já realizadas no estado, resultado de investimentos no âmbito do ensino público, tidos como fundamentais pelo Estado Novo. A importância atribuída à casa de ensino que servia de referência no estado seria o principal motivo do investimento para a construção do novo prédio de proporções grandiosas. Mas a realidade dos fatos desafiava o que era previsto nos discursos. No lançamento da pedra fundamental do novo edifício, as construções previstas para a Educação Física ainda se resumiam aos dois salões e um pátio arborizado para recreio, além de um salão para os exercícios de ginástica. No entanto, pouco tempo após o início das obras, percebeu-se que, construído da forma que havia sido planejado, o prédio do CEP ocuparia todo um quarteirão no centro da cidade, não restando espaço para as instalações da Educação Física, o que faria com que o governo necessitasse disponibilizar mais uma quadra, desapropriando uma série de residências que já estavam estabelecidas. Com a interrupção das obras, decorrente da impossibilidade de construção da área destinada à Educação Física, alguns meses mais tarde, o governo adquiriu um novo terreno um pouco distante do centro e em lugar elevado. As obras foram iniciadas em 1944 e, em 29 de março de 1950 - data comemorativa do aniversário da cidade de Curitiba -, foi entregue o novo e suntuoso prédio do CEP, considerado, à época, o maior estabelecimento de ensino do gênero não só do Brasil mas também da América do Sul, segundo Straube (1993). Essas considerações são importantes para entendermos o processo de valorização da disciplina de Educação Física, tanto no CEP como na instrução pública paranaense em geral.

\section{Novo prédio, novos espaços, novos conteúdos? A educação física no Colégio Estadual do Paraná na década de 1950}

Ao analisarmos imagens do Colégio Estadual do Paraná nos anos 1950, podemos perceber que o espaço tomado pelo novo edifício do CEP possuía proporções grandiosas, em comparação com as demais construções que o circundavam. Localizado estrategicamente em uma região ligeiramente mais elevada, sua arquitetura e expressividade chamavam a atenção pela imponência e sinalizavam para uma grande realização do governo. Partindo do pressuposto de que a arquitetura pode ter um papel fundamental na criação de um lugar e que ainda pode assumir uma importante função na formação de identidades, 
personalidades e "almas" dos educandos, podemos sugerir que esse novo edifício representava o valor atribuído a uma "grandiosa" instituição, responsável por um "grande" projeto político, demarcado pela afirmação de uma determinada perspectiva de desenvolvimento nacional. Se compararmos ainda a área tomada pelo prédio escolar e os espaços destinados à Educação Física, ou seja, se analisarmos o "espaço-escola" proposto por Agustín Escolano, podemos atribuir à Educação Física uma significativa importância no currículo do CEP. Para o autor, o edifício-escola

serviu de estrutura material para colocar o escudo pátrio, a bandeira nacional, as imagens e pensamentos de homens ilustres, os símbolos da religião, algumas máximas morais e higiênicas [...]. Isso expressa toda uma instrumentação da escola a serviço dos ideais nacionais, religiosos e sociomorais (1998, p. 40).

A construção da área destinada à Educação Física no CEP, sem dúvida, foi um marco para a época. A inauguração das instalações do novo prédio deuse em 29/03/1950, mas somente no ano seguinte, em 27 de outubro, a área de esportes seria totalmente finalizada e entregue. As instalações da Educação Física consistiam em: estádio de futebol com arquibancada, campo de futebol de 95x60 m, 6 balizas para corrida, 2 caixas de salto em distância e tríplice, 2 caixas de salto com vara, 2 caixas de salto em altura, 4 círculos para arremesso de peso, 2 círculos para arremesso de martelo, 1 pista de $360 \mathrm{~m}, 2$ piscinas, uma olímpica e uma para aprendizagem, 1 ginásio com instalações higiênicas e vestiários para alunos, alunas, professores e professoras, 1 cancha para ginástica, basquetebol e voleibol com piso de madeira, no ginásio, contando com duas tabelas completas e dois esticadores de redes de voleibol, 2 canchas de voleibol com piso de asfalto e arquibancadas de cimento, 2 canchas de basquetebol com piso de asfalto com as dimensões de $15 \times 28 \mathrm{~m}$ e $15 \times 26 \mathrm{~m}$, 1 pórtico olímpico com escadas verticais e inclinadas, hastes verticais e cordas (ARQUIVO PÚBLICO DO PARANÁ, 1952).

Além dessas instalações, ainda estava disponibilizada uma considerável área para a circulação dos alunos, em alas separadas para ambos os sexos. É importante aqui estabelecer uma comparação entre as novas instalações do CEP e as Diretrizes para a Educação Física nos estabelecimentos de ensino secundário, publicadas em 1947. Sendo uma instituição modelar, o CEP deveria seguir tais orientações vindas do Ministério da Educação e Saúde. Nesse documento estavam indicados os registros relativos às instalações e às quantidades mínimas 
de materiais que os estabelecimentos deveriam satisfazer. No item Instalações, o mínimo, segundo as Diretrizes, consistia em: "caixa para saltos em altura e distância, com as respectivas pistas; aparelho para saltos em altura; uma barra dupla; trave à altura de $1,10 \mathrm{~m}$; alvo para arremesso de bolas; pórticos com hastes, cordas e escalas (dispensável nos estabelecimentos exclusivamente femininos)" (p. 9). A predominância de instalações direcionadas aos esportes é mais um indício de que a Educação Física estava tomando uma outra configuração, direcionando cada vez mais seus trabalhos para presença dos esportes como conteúdos predominantes. A intenção era que as instituições possuíssem um estádio com as instalações para exercícios ginásticos e também a prática de alguns esportes, em especial, segundo a fonte acima, o atletismo. A relação de materiais solicitada pelas Diretrizes e a adquirida pelo CEP também indicam esse processo que podemos chamar de esportivização. A lista de espaços construídos e uma considerável lista de materiais adquiridos para as aulas de Educação Física, além dos depoimentos dos professores Ernani Straube e Ivete Luz Buck Silva, reforçam a hipótese da afirmação dos esportes - e não somente o atletismo - como conteúdos predominantes: "Depois [no prédio novo do CEP] viemos a ter vôlei, turma de vôlei, turma de basquete, atletismo, natação, tudo isso já no prédio novo, mas lá no prédio velho, lá não tinha condições..." (ERNANI STRAUBE, 2003, p. 8).

\begin{abstract}
Depois quando mudou-se para o Colégio Estadual, então houve a expansão do método, aí dávamos jogos, dávamos natação e tudo o que compõe uma aula de Educação Física. E aí tinham dias determinados. Tinha um dia na semana em que era só natação. A turma inteirinha ia para a piscina e a gente ensinava como nadar (IVETE BUCK SILVA, 2004, p. 7).
\end{abstract}

Com a entrega das obras do novo edifício do CEP, as condições de espaço e de materiais para as aulas de Educação Física tão requisitadas nos anos anteriores, estavam disponibilizadas de maneira mais do que satisfatória, se compararmos com as solicitações mínimas das Diretrizes. Contudo, essa grandiosidade das instalações esportivas da instituição parece ser um caso sui generis, pelo menos no que refere ao ensino público paranaense. 


\section{Nos anos 1970 a "modernidade" relacionada ao espaço ainda não chegara...}

Sabe-se que uma das metas políticas para a expansão da Educação Física na década de 1970 no Brasil era justamente o incremento de recursos financeiros e materiais. Isso, por si só, nos faz questionar a materialização daqueles discursos de 30 ou 40 anos antes, para os quais a educação escolar e a Educação Física ensejariam o "novo" no plano pedagógico. Aparentemente o "novo" insistia em permanecer velho! Sobre tudo no que se refere as condições objetivas - entre elas, o espaço - para a realização das aulas de Educação Física, mesmo que sob o primado do modelo esportivo. Recorrendo também nesse caso ao depoimento dos professores dos anos 70, vemos que a maioria das escolas ressentia-se da falta de espaço e material adequados, o que implicava uma constante improvisação e adaptação dos recursos à exigências dos programas. Considerando que a Prefeitura Municipal de Curitiba desenvolveu uma política de Educação Física e, ainda assim, apresentava essas dificuldades, podemos deduzir que naqueles lugares em que a Educação Física ainda não era objeto de uma maior sistematização, a situação fosse bem pior, o que nos permite relativizar a implementação in toto do próprio ideário oficial que, como vimos vem pelo menos dos anos 40 do séc. XX.

Uma das características da Educação Física brasileira no período da ditadura militar foi justamente a busca da sua afirmação. Um dos elementos dessa afirmação passava, sem dúvida, pelo incremento do apoio físico necessário para o seu desenvolvimento. O Diagnóstico da Educação Física e Desportos no Brasil, de 1971, é enfático ao destacar a necessidade de investimento em infraestrutura, de intercâmbio, de melhora nos padrões de formação etc. Quanto aos dois últimos aspectos, em outra ocasião já foram observadas evidências do seu desenvolvimento no Brasil (TABORDA DE OLIVEIRA, 2003). Naquilo que respeita às instalações e materiais, sabemos da precariedade manifesta nos programas de algumas unidades educacionais. Sabemos também que a lei - decreto 69.450/71 - chega ao requinte de estabelecer o número de sessões semanais de Educação Física, o espaço mínimo necessário para cada aluno, além de outros padrões de referência. Também sabemos, pelos depoimentos de alguns professores, que o Programa de Educação Física teria sido adaptado à lei, o que faz supor que incorporou a sua letra. O Programa, por sinal, pela sua própria ênfase esportiva, fazia supor uma disponibilidade bastante confortável de material, instalações, equipamentos etc. $\mathrm{O}$ que nos dizem os professores sobre essas considerações acima? Vejamos, por exemplo, o professor Aluísio da Rosa: 
Então, foi uma época assim de muita fartura. Nós levávamos sacos de bolas de vôlei, de basquete, de borracha, maça, arco, entendeu? Material de atletismo: peso, disco, dardo. Colchões de ginástica. A escola estava abarrotada. Então você municiava o professor; ele tinha, vamos dizer, material. Ele não poderia, primeiro, reclamar de espaço porque ele tinha quadra, tinha tudo. Material ele tinha de sobra $[\ldots]$.

Devemos relembrar que o professor Aluísio da Rosa aquela época (1974/1975) era coordenador de Educação Física da Prefeitura Municipal de Curitiba, bem como comandava uma equipe de supervisores. $\mathrm{O}$ trecho citado acima foi extraído justamente de uma passagem do seu depoimento em que ele justifica a prática da supervisão por parte da Prefeitura. Observe-se que ele é taxativo no que diz respeito à disponibilidade de material e de instalações para os professores desenvolverem suas práticas. Mas qual era a situação de uma das maiores escolas da rede municipal no mesmo período? Expõe a professora Hermínia Piazzetta Xavier:

Nós tínhamos fartura de material. Espaço era exíguo. Nós não tínhamos nada. Nós íamos para rua, nós íamos na frente das casas que tinham uns vazios, terreno baldio; aproveitávamos tudo. Aqui estava sendo construído e aí começou [...] Fizeram uma quadrinha pequenina lá nos fundos e gente usava aquela; dividia entre a gente.

E continua:

Com o tempo fizeram a quadra de cima. Com uma escola deste tamanho o espaço para Educação Física é muito pequeno. Nós não temos espaço aqui. Todo mundo acha que tem, mas para uma escola que tem 40 turmas em um período, a quadra é muito pequena. Eu sempre costumei ir para rua. Peguei quadras lá nos fundos, no Centro Social, no Arion. [...] Porque não havia espaço. Então cada um lutava pelo seu espaço.

Estamos nos anos iniciais da década de 1970. Ao que parece as impressões do então supervisor não se confirmam. Ainda que a escola em questão gozasse de fartura de material, o que é confirmado pelo depoimento da professora Hermínia, a disponibilidade de espaço adequado era sofrível. Vários elementos expostos 
nesse depoimento nos ajudam a questionar em que medida as postulações oficiais poderiam ser cumpridas. Primeiramente, é sabido que a prática esportiva, modelo previsto no ideário oficial e, como mostramos na primeira parte deste trabalho, prevalescente desde pelos menos os anos 1950, implica disponibilidade de material e espaço adequados. Pode parecer óbvio, mas não é possível desenvolver o esporte, seja o voleibol, o basquetebol, a ginástica ou qualquer outro, sem um local adequado para essa prática. Ao indicar que as aulas se davam nas ruas, em terrenos baldios etc., a professora Hermínia nos oferece elementos para afirmar que, no máximo, poderia acontecer nessas aulas uma aproximação do que seriam os esportes. Se partirmos do pressuposto que o espaço escolar é essencialmente conformador do currículo, como advertem Viñao (1996) e Viñao; Escolano (1998) devemos admitir que uma efetiva esportivização das aulas de Educação Física só poderia ter ocorrido com a disponibilidade daquele espaço determinado pelos códigos esportivos. Não se trata, pois, de ter apenas espaço livre disponível, mas, sobretudo, de ter o espaço adequado, com os seus equipamentos, suas demarcações etc. Talvez por ter consciência desses limites a professora tenha ironizado sobre a capacidade criativa do professor de Educação Física. A falta do espaço adequado ao desenvolvimento de uma determinada prática é um indicativo poderoso de que ela não poderia ter se desenvolvido como era desejável pelo formulador da política pública. Ou seja, ao professor restaria a improvisação. E a improvisação, além de ter sido denunciada desde os primeiros anos do Programa, é justamente um dos elementos que a tecnologia educacional tenta combater, o que mostra como a realidade é rebelde à lógica tecnocrática propugnada pelos militares e seus seguidores. Neste sentido, aquilo que estava expresso na lei e nos programas simplesmente não podia ser desenvolvido na realidade daquela escola, uma vez que havia um abismo entre a formulação legal e a condição real da escola. É importante observar que, mesmo quando se efetivou a disponibilidade de um espaço apropriado para a prática de esportes, a aula não acontecia conforme o desejado em função da inadequação daquele espaço. Se a legislação, mais especificamente o Decreto 69.450/71, tanto quanto o Programa, falam em padrões de referência que determinam a separação das turmas por sexo, a destinação de um espaço específico para cada aluno etc., o fato de os professores precisarem dividir espaços tão exíguos é um indicativo de que a aula não poderia ocorrer como estava previsto nos Programas. E a "luta por um espaço" não parece indicar que as condições de trabalho, numa escola que foi concebida como modelo, fossem as ideais previstas na legislação. Isso 30 anos depois da propalada afirmação do esporte como "motor" das aulas de Educação Física.

O depoimento da professora Hermínia ganha em força quando lembramos que ela trabalhou por longos 25 anos na mesma escola, tendo, portanto, acom- 
panhado os altos e baixos das tentativas de valorização da Educação Física. Se nos anos de implantação do Programa, da supervisão, da lei e, por fim, da perspectiva esportiva para a Educação Física, os professores eram compelidos a improvisar em função das dificuldades com o espaço, o número de alunos, o tempo; se alguns anos depois esses problemas permaneciam e a eles se acrescia a falta de material, não poderíamos afirmar que, ao longo de todo aquele período, a aula de Educação Física não aconteceu como previam o Programa e o ideário oficial? Não se tratava somente da adesão ou da boa vontade dos professores. Tratava-se principalmente do não-oferecimento de condições de trabalho adequadas àquilo que estava sendo postulado por parte dos próprios órgãos governamentais. Assim, a lei e o Programa não seriam mais do que uma prescrição tecnicamente coerente, mas provavelmente de alcance muito mais largo do que comportava a realidade escolar, ainda que tenham sido influenciados pelas demandas dessa mesma realidade. Ou seja, a "perfeição" tecnocrática da política desses governos militares não só esbarrava na realidade ordinária da escola como mostrava a fragilidade dessa forma de gestão da cultura.

Para o professor Clodoaldo Rossa, eram o voluntarismo e a iniciativa dos próprios professores de Educação Física as principais armas contra a falta de recursos: "A gente estava preocupado em melhorar a Educação Física na escola como um todo, procurando melhorar os locais, procurando material. A Prefeitura não mandava material, então como é que a gente ia conseguir dinheiro para materiais?". A escola à qual se refere o professor Clodoaldo era considerada, senão a principal, uma das principais escolas da prefeitura naqueles anos. Tratase da Escola Papa João XXIII. O professor indica que tanto os "locais" quanto o material não supriam as necessidades da escola. Mais marcante ainda é o fato de esse professor reconhecer-se como uma fiel seguidor do "tecnicismo", como um professor que tinha o esporte como fim último das aulas de Educação Física. Num momento de centralização absoluta das decisões e dos recursos, vemos a realidade escolar levantar-se contra o planejamento absoluto. Não fossem as iniciativas do professor e dos seus alunos, "atletas", talvez aquilo que estava proclamado na lei não pudesse ter sido desenvolvido. A crença do próprio professor na pertinência daquele modelo parece tê-lo movido a buscar as condições ideais para o desenvolvimento das suas aulas. Condições essas eram negadas justamente pelos órgãos que orientavam como a aula de Educação Física deveria acontecer. Mas como é próprio das normas que se prendem àquilo que deveria ser, sua aplicação não poderia ocorrer sem o atendimento das exigências básicas necessárias para o seu desenvolvimento. Como em tantas outras dimensões da cultura, a Educação Física parece não ter escapado à incongruência entre a realidade brasileira e as determinações da tecnocracia. E aqui estamos diante de um sistema que inovava e buscava avidamente adaptar-se à norma legal. $\mathrm{E}$ a 
ideia de "modernização" ainda era central nas políticas oficiais daqueles anos. Se tomarmos como referência a realidade de algumas escolas estaduais tudo indica que as condições eram ainda mais precárias.

A escola não tinha nada vezes nada. Em 73 estavam construindo a escola ainda. Eu dava aula em um campo de futebol que era de uma fábrica de madeira que havia. Não me lembro se era só de corte, não sei [...]; só sei que era só um campo de futebol que essa fábrica de madeira cedia para a escola. Um frio do "capeta", quando geava - aquilo era uma baixada - e congelava de baixo para cima!

A precariedade de condições é transparente nesse depoimento da professora Carmen Piovesan:

não havia local, não havia material, tudo que era possível desenvolver era a corrida.

Fiz muita corrida, porque não tinha material, não tinha nada [...] Eu sempre fui assim: quando entrava na escola fazia, montava, carpia, e não sei o quê, e quando eu saía da escola, construíam a quadra (risos). Que nem a cerca do [bairro do] Xaxim: eu com as crianças cortamos, cavoucamos os buracos e assentamos serragem para fazer salto em distância. Era a única coisa que dava para fazer!

Novamente se manifesta o voluntarismo de uma professora na busca de condições mínimas ideais para o desenvolvimento do seu trabalho. Afora todas as dificuldades relatadas pelos professores, parece claro que em muitos casos eles não esperavam pelas iniciativas de quem quer que fosse. Imbuídos do compromisso de desenvolver suas atividades, os professores lançavam-se a uma série de tarefas que poderiam minimizar os efeitos da falta de recursos para o desenvolvimento de suas aulas, tarefas que deveriam ser responsabilidade do poder público.

Os depoimentos desses professores que atuaram em épocas distintas no ensino público da capital paranaense parecem corroborar um elemento fundamental do currículo em ação: a aula de Educação Física era desenvolvida a partir de uma riqueza de experiências dos professores, experiências que incluíam elementos da sua formação universitária inicial e da sua formação permanente. 
Mas aquelas experiências incluíam também formas diversas de reação diante da adversidade aqui manifesta pela falta de recursos adequados para a realização do seu trabalho. Em muitos casos o professor acabava determinando o que era ou não adequado para o desenvolvimento das suas aulas. As condições objetivas estavam dadas: material, espaço, equipamento e perfil da comunidade. A realidade dos professores rebelava-se contra o absoluto da lei e do Programa. A sua atuação revelava as reais possibilidades de desenvolvimento da aula de Educação Física. Reagiam diante das agruras do dia-a-dia com as armas que dispunham. Talvez uma dessas armas possa ser caracterizada como um "voluntarismo", um "fazer por fazer", uma vez que a própria adversidade das condições de trabalho seria um empecilho para o desenvolvimento e a organização da Educação Física escolar para além daquela compreendida como atividade, como gostaria Souza Jr. (1999) e toda uma larga tradição investigativa da Educação Física brasileira. A falta de espaços e materiais adequados, além de condições outras como o perfil da comunidade, em alguns casos simplesmente negou o absoluto do planejamento com base no esporte e em outros possibilitou o desenvolvimento de atividades que negavam, em última análise, aquela premissa esportiva. Nesse particular as experiências também eram múltiplas e é impossível reduzi-las a quaisquer esquemas, regularidades ou generalizações. Mas as condições adversas do trabalho do professor parecem ter sido uma marca, a qual calaria fundo no seu imaginário:

\begin{abstract}
Agora, eu não gostaria de dar Educação Física do jeito que eu dava. Porque a gente entra para dar aula às $7 \mathrm{~h} 30 \mathrm{~min}$ da manhã, dá aula até $17 \mathrm{~h} 45 \mathrm{~min}$, e ninguém diz para a professora: "Cuidado com seu corpo, sua pele, seu cabelo, sua saúde". Eu perdi a voz, perdi a saúde; eu tenho dores no corpo. E ninguém valorizou o que eu fiz. Entende? Eu fui desviada de função por perder a voz. Porque nós ficamos sujeitos ao sol, à poeira, à garoa, ao frio. E você sabe que o tempo fecha e abre o dia inteiro; e você está ali, naquilo. É cansativo, é desgastante, é irritante às vezes, mas mesmo assim... Eu louvo a Educação Física, mas eu não gostaria mais de voltar dar aula. Deixar o campo para os jovens (HERMÍNIA PIAZZETTA XAVIER).
\end{abstract}

Levamos em consideração uma escola modelo atípica, ainda que pública, e um conjunto de escolas que poderíamos caracterizar com típicas ou comuns. Cremos que essa diferença, dada o nosso objetivo maior, não compromete o nosso esforço de mostrar como o espaço - e a sua falta - foram determinantes para a afirmação ou negação de uma determinada perspectiva para o ensino de Educação Física nas escolas analisadas, ainda que os discursos oficiais propa- 
lassem a modernização do ensino. Em dois momentos de forte desenvolvimento econômico a educação escolar parecia ainda relegada a um plano secundário nas políticas públicas. A monumentalidade do CEP a partir dos anos 1950 contrasta fortemente com a precariedade da escola pública de 25 anos depois (note-se que estamos na mesma cidade). As dependências do CEP receberam diversos eventos esportivos, inclusive internacionais; as olimpíadas colegiais estaduais também começaram ali. A instituição se tornou uma referência no que se refere ao esporte estudantil. Já, no caso das escolas dos anos 1970, nelas ainda grassava a falta de atenção com o estabelecimento de condições mínimas para o desenvolvimento de um modelo de ensino proclamado até pelo ideário oficial, qual seja, o modelo das progressões pedagógicas com base nos esportes. Tido como algo avançado naqueles anos, o esporte aparecia na retórica oficial como elemento modernizador das práticas escolares. Mas as condições reais para a sua realização pareciam atualizar o velho descompromisso com a qualidade da escola pública, manifesta, no nosso exemplo, pela carência e inadequação dos espaços para o desenvolvimento das aulas.

Extrapolados os argumentos sobre o espaço escolar cabe indagar sobre as possibilidades de realização de um "projeto moderno" de reforma da cultura - aqui incluída a escolarização - em um país fortemente marcado por absurdas diferenças econômicas e pela exclusão cultural. Afinal, naquelas décadas que muitos gestores, políticos e intelectuais - militares ou não - desenvolveram retóricas em torno da modernização da cultura brasileira, nossa sociedade produzia um dos mais perversos e desiguais sistemas econômicos do mundo. Deveria causar espanto que a retórica modernizadora não tivesse saído do papel?

\section{REFERÊNCIAS}

CHAVES JUNIOR, Sergio Roberto. A Educação Física do Ginásio Paranaense ao Colégio Estadual do Paraná: contribuições para a construção de uma história de uma disciplina escolar (1931-1951). Dissertação (Mestrado em Educação) - UFPR, Curitiba, 2004.

LINHALES, Meily Assbú. A escola, o esporte e a "energização do caráter": projetos culturais em circulação na Associação Brasileira de Educação (1925-1935). Tese (Doutorado em Educação) - UFMG, Minas Gerais, 2006. 
SOUZA JUNIOR, Marcílio. O saber e o fazer pedagógicos: a Educação Física como componente curricular...? ...isso é história! Recife: Edupe, 1999.

STRAUBE, Ernani Costa. Do Licêo de Coritiba ao Colégio Estadual do Paraná. Curitiba: Fundepar, 1993.

TABORDA DE OLIVEIRA, Marcus Aurélio. Educação Física escolar e ditadura militar no Brasil (1968-1984): entre a adesão e a resistência. Bragança Paulista: Editora da Universidade São Francisco, 2003.

VAGO, Tarcísio Mauro. Início e fim do século XX: maneiras de fazer educação física na escola. Caderno Cedes, Campinas, v. 19, n. 48, ago. 1999.

VIÑAO FRAGO, Antonio. Historia de la educación e historia cultural: posibilidades, problemas, cuestiones. Revista Brasileira de Educação, São Paulo, Anped, n. 0, set./ dez, 1995.

. Espacio y tiempo, educación e historia. Morelia: IMCED, 1996.

. Do espaço escolar e da escola como lugar: propostas e questões. In: VIÑAO FRAGO, Antonio; ESCOLANO, Agustín. Currículo, espaço e subjetividade: a arquitetura como programa. Trad. Alfredo Veiga Neto. Rio de Janeiro: DP\&A, 1998.

\section{FONTES}

ARQUIVO GERAL DO COLÉGIO ESTADUAL DO PARANÁ. Inspetoria Federal - Correspondência. Ofícios e telegramas expedidos de 1934 a 1941.

. Cópia dos Relatórios de Educação Física dos Cursos: Fundamental e Complementar - Ano Letivo de 1941.

ARQUIVO PÚBLICO DO PARANÁ. Relatório apresentado à Diretoria do estabelecimento pelo Professor Hamilton Saporski Dal'lin, Chefe do Departamento de Educação Física, 1952.

MUSEU DO COLÉGIO ESTADUAL DO PARANÁ. Cópia de Ofícios - Diretoria, 1934.

PROFESSOR ALUÍSIO DA ROSA. Entrevista. Curitiba, 30 de abril de 1998. 22 p. 
PROFESSOR CLODOALDO JOSÉ ROSSA. Entrevista. Curitiba, 27 de abril de 1998.37 p.

PROFESSOR ERNANI COSTA STRAUBE. Entrevista. Curitiba, 22 de outubro de 2003. 16 p.

PROFESSORA CARMEN LÚCIA DE CAMARGO PIOVESAN. Entrevista. Curitiba, 14 de maio de 1998. 29 p.

PROFESSORA HERMÍNIA PIAZZETTA XAVIER. Entrevista. Curitiba, 28 de outubro de $1998.49 \mathrm{p}$.

PROFESSORA IVETE LUZ BUCK SILVA. Entrevista. Curitiba, 16 de abril de 2004. $15 \mathrm{p}$.

PROFESSOR MÁRIO BASSÓI. Entrevista. Curitiba, 10 de outubro de 2003. 24 p. 